\title{
Cancer chemotherapy: targeting folic acid synthesis
}

This article was published in the following Dove Press journal:

Cancer Management and Research

18 November 2010

Number of times this article has been viewed

\author{
Nicole Hagner \\ Markus Joerger \\ Department of Medical Oncology, \\ Cantonal Hospital, St Gallen, \\ Switzerland
}

Correspondence: Markus Joerger Department of Oncology and Hematology, Cantonal Hospital, Rorschacherstr. 95, 9007 St Gallen, Switzerland

Tel +4I 7| 494IIII I

Fax +4I 7| 4942563

Email markus.joerger@kssg.ch
Abstract: Antifolates are structural analogs of folates, essential one-carbon donors in the synthesis of DNA in mammalian cells. Antifolates are inhibitors of key enzymes in folate metabolism, namely dihydrofolate reductase, $\beta$-glycinamide ribonucleotide transformylase, 5 '-amino-4'-imidazolecarboxamide ribonucleotide transformylase, and thymidylate synthetase. Methotrexate is one of the earliest anticancer drugs and is extensively used in lymphoma, acute lymphoblastic leukemia, and osteosarcoma, among others. Pemetrexed has been approved in combination with cisplatin as first-line treatment for advanced non-squamous-cell lung cancer, as a single agent for relapsed non-small-cell lung cancer after platinum-containing chemotherapy, and in combination with cisplatin for the treatment of pleural mesothelioma. Raltitrexed is approved in many countries (except in the United States) for advanced colorectal cancer, but its utilization is mainly limited to patients intolerant to 5-fluorouracil. Pralatrexate has recently been approved in the United States for relapsed or refractory peripheral T-cell lymphoma. This article gives an overview of the cellular mechanism, pharmacology, and clinical use of classical and newer antifolates and discusses some of the main resistance mechanisms to antifolate drugs.

Keywords: antifolates, cancer, molecular pharmacology, pemetrexed, methotrexate, folate metabolism

\section{Introduction}

Folates are essential, one-carbon donors in the synthesis of purines, pyrimidines, serine, and methionine, all critical to de novo synthesis of DNA in mammalian cells, as they lack the capacity to synthesize folates and require these anionic hydrophilic molecules to be transported into the cells via sophisticated transport systems (reduced folate carrier, RFC). After folate was discovered to be vital to many cellular processes, the antifolates aminopterin and methotrexate (MTX) were synthesized in the early 1940s. ${ }^{1}$ In 1948, aminopterin was the first drug to induce temporary remissions in childhood leukemia. ${ }^{1,2}$ Only 10 years later, MTX was part of a therapy regimen that was first shown to cure some selected solid tumors, namely choriocarcinoma. ${ }^{3}$ MTX is still used in the treatment of a variety of tumors, including acute lymphocytic leukemia, ${ }^{4}$ breast cancer, ${ }^{5}$ osteosarcoma, ${ }^{6}$ primary central nervous system lymphoma, ${ }^{7}$ and head and neck cancer. ${ }^{8}$ Above all, it is also used in certain autoimmune diseases, such as rheumatoid arthritis or psoriasis. Recently, the newer antifolate pemetrexed or multitargeted antifolate (MTA) has been established in the first-line treatment of mesothelioma ${ }^{9}$ and non-squamous, non-small-cell lung cancer (NSCLC).$^{10} \mathrm{An}$ important task for the future is treatment individualization, eg, by identifying genetic variations in drug pathwayassociated genes with an important impact on clinical outcome in patients receiving 
antifolates ${ }^{11-13}$ or the use of therapeutic drug monitoring (TDM), eg, with MTX, enabling adequate drug exposure in all patients. ${ }^{14,15}$

\section{Cellular folate metabolism}

Folates (pteroylglutamates) belong to the family of $\mathrm{B}_{9}$ vitamins that are essential to mammalian cells. They form a family of cofactors based on the structure of folic acid (2- $\mathrm{NH}_{2}-4-\mathrm{OH}-$ pteroylglutamic acid). Folic acid undergoes intracellular reduction first to dihydrofolate and then to tetrahydrofolate (THF). Both reduction steps are mediated by dihydrofolate reductase (DHFR). The major dietary form of folates is $5^{\prime}$-methyl-THF ( $5^{\prime}$-MTHF). Together with homocysteine, MTHF is converted to methionine and THF, a vitamin- $\mathrm{B}_{12}$-dependent step that is mediated by methionine synthase. THF is the main substrate for folylpolyglutamate synthetase (FPGS), which progressively adds glutamates at the $\gamma$-carboxyl residues. The resulting folate polyglutamates are polyanionic molecules that can no longer be transported through the lipophilic cell membrane. These folate polyglutamates are the biologically active form of folates, as they serve as one-carbon donors in de novo synthesis of purines, thymidylate, and polyamines. Furthermore, folates are required for the synthesis of S-adenosyl methionine, which promotes methylation of DNA, histones, lipids, and neurotransmitters. ${ }^{16}$

\section{Antifolate drug metabolism}

As structural analogs of folates, antifolates use the same transport systems to enter the cells, namely the reduced folate receptor (RFC), folate receptors (FR), and the recently discovered proton-coupled folate transporter (PCFT) or soluble carrier 46A1 (SLC46A1). ${ }^{16}$ The RFC plays a dominant role in cellular uptake of antifolates, as it has low affinity to its main endogenous ligand MTHF. Its affinity to antifolates varies from low for MTX to high for talotrexin (PT-523). ${ }^{17}$ The RFC works as an anion exchanger that utilizes the gradient built up by an asymmetrical distribution of organic phosphates across cell membranes. ${ }^{18,19}$ The RFC is expressed both in tumor cells and normal tissue,${ }^{20}$ limiting the tolerability of antifolates. On the contrary, the folate receptors FR- $\alpha$ and FR- $\beta$ are overexpressed at the surface of some tumor cells, making these tumors vulnerable to antifolate drugs, ${ }^{21,22}$ The FR family consists of two cell-surface receptors (FR- $\alpha$ and FR- $\beta$ ) and a constitutively secreted isoform (FR- $\gamma$ ) ${ }^{23,24}$ FR- $\alpha$ is expressed in a number of normal epithelial cells as well as in a number of carcinomas, with the exception of carcinomas of the head and neck. ${ }^{21}$ FR- $\beta$ serves as a myeloid differentiation marker and is overexpressed in a variety of nonepithelial malignancies, ${ }^{21,25}$ whereas the expression of FR- $\gamma$ is restricted to hematopoietic tissues. ${ }^{24,26}$ In contrast to the high-capacity and low-affinity RFC, transport by FR- $\alpha$ and FR- $\beta$ is by low-capacity and high-affinity endocytosis. ${ }^{27}$ After antifolate transport to the endosomal compartment, transport to the intracellular compartment involves the PCFT. ${ }^{28,29}$ Accordingly, mutations in the gene encoding for PCFT have been shown to cause rare hereditary folate malabsorption. ${ }^{29}$ In addition to its role in folate endocytosis, PCFT also serves as a high-affinity folate-proton symporter that is important for the intestinal absorption in the proximal small intestine..$^{30}$ Besides these specific folate transporters, a number of other transport systems have been described to be involved in the efflux of antifolates, including the multidrug resistance-associated proteins MRP1-5 and the breast cancer resistance protein (BCRP or ABCG2). ${ }^{31,32}$

Intracellularly, the classical antifolates undergo polyglutamation by FPGS, resulting in effective intracellular retention and increased affinity of the antifolates to their target enzymes. ${ }^{33-36}$ The nonclassical lipophilic antifolates such as talotrexin or trimetrexate (TMQ) are not substrates of FPGS and do not require activation by polyglutamation for anticancer activity. ${ }^{37}$

\section{Cellular targets: TYMS, DHFR, GARFT, and AICARFT}

Antifolates are inhibitors of key enzymes in folate metabolism, namely DHFR, $\beta$-glycinamide ribonucleotide transformylase (GARFT), 5'-amino-4'-imidazolecarboxamide ribonucleotide transformylase (AICARFT), and thymidylate synthetase (TYMS). GARFT and AIRCARFT are two key enzymes of the de novo purine biosynthesis. In a first step, GARFT enables the formation of the purine imidazole ring of purines. The substrate for this reaction is $10^{\prime}$-formyl-THF, which is synthesized from THF and formate, a step mediated by $10^{\prime}$-formyl-THF synthetase. In a second step, AICARFT generates inosine monophosphate, which serves as the precursor for purine nucleotides adenylate (AMP) and guanylate (GMP). DHFR catalyzes the reduction of DHF to $5^{\prime}, 6^{\prime}, 7^{\prime}, 8^{\prime}-$ THF, which is converted to $5^{\prime}, 10^{\prime}$-methyltetrahydrofolate $\left(5^{\prime}, 10^{\prime}\right.$-MTHF), the substrate for TYMS. ${ }^{38}$ TYMS catalyzes the initial step in DNA synthesis, in which deoxythymidine monophosphate (dTMP), a precursor of DNA synthesis, is generated from deoxyuridine monophosphate (dUMP), resulting in the oxidation of MTHF to DHF. This metabolic step is essential for de novo synthesis of thymidine nucleotides for DNA synthesis. DHFR was the first enzyme to be 
identified as a cellular target for the antifolates aminopterin and MTX. ${ }^{39}$ The latter exhibits its anticancer effect by almost irreversible inhibition of DHFR, with subsequent disruption of purine and pyrimidine synthesis. ${ }^{40}$ Newer antifolates have been designed with a higher affinity toward DHFR, eg, talotrexin, with a 15-fold increased affinity when compared with MTX. ${ }^{37}$

\section{Mechanisms of resistance}

Antifolate resistance might result from impaired cellular influx or increased efflux, impaired polyglutamation, increased expression, or mutation of cellular targets, or intracellular accumulation of THF cofactors. Various transportresistant phenotypes have been described in MTX-resistant cell line models, some of them resulting from mutations of the $R F C$ gene, ${ }^{41-43}$ and others from RFC overexpression. ${ }^{44-46}$ A genetic polymorphism within the $R F C$ gene $(80 \mathrm{G}>\mathrm{A})$ results in replacement of arginine in position 27 with histidine, ${ }^{47}$ and is associated with a worse clinical outcome in children with acute lymphoblastic leukemia (ALL) receiving MTX. ${ }^{48}$ In osteosarcoma, which is known for its intrinsic resistance to conventionally dosed MTX, mutations at the 3'-UTR and promoter methylation of the RFC were described. ${ }^{49}$ The role of FR is less well characterized and more controversial. Although overexpression of FR- $\alpha$ was found to predict resistance to platinum-based chemotherapy in ovarian cancer patients, ${ }^{50}$ suppression of FR expression by gene methylation was also found as a potential mechanism of resistance. ${ }^{51}$ Similarly, hypermethylation of the PCFT gene (SLC46A1) was found in a resistant HeLa cell line. ${ }^{52} \mathrm{Mul}-$ tidrug resistance-associated proteins (MRP or ABCC) 1-4 confer the efflux of MTX and have been shown to potentially confer resistance to MTX in cell line models. ${ }^{53,54}$ However, MTX polyglutamates have low affinity toward the ABCC transporters, which is why this type of resistance might not be clinically relevant. However, breast cancer resistance protein (BCRP or ABCG2) also transports polyglutamates out of the cell, and mutations within the $A B C G 2$ gene (at amino acid position 482) have been shown to confer resistance to various antifolates. ${ }^{55,56}$ Overexpression of P-glycoprotein (MDR1) is suggested to be important for antifolate resistance in the presence of a defective RFC or in case high doses of MTX are administered. ${ }^{57}$ Impaired polyglutamation is another mechanism that is of special importance for the classical antifolates that undergo extensive polyglutamation to be active. Finally, amplification of the gene encoding for DHFR has been identified in ALL, ${ }^{58}$ ovarian cancer, ${ }^{59}$ and soft-tissue sarcoma ${ }^{60}$ as a potential mechanism of resistance to MTX, but the clinical relevance of such amplifications is unclear at present. ${ }^{61}$

\section{Specific substances Classical antifolates}

The classical antifolates have a similar structure to MTX, utilize the RFC for entering human cells, and are subject to intracellular polyglutamation.

\section{MTX}

MTX is one of the earliest anticancer drugs and is extensively used in lymphoma, acute lymphoblastic leukemia, and osteosarcoma. The drug competitively inhibits DHFR and, to a lesser extent, GARFT, AICARFT, and TYMS. Although thymidylate depletion is the main cytotoxic driver of MTX, inhibition of GARFT and AICARFT also results in impaired purine synthesis. As a result of their inability to synthesize DNA and RNA, the malignant cells are unable to proliferate and cause further damage, resulting in cell apoptosis.

\section{Pharmacology}

7-Hydroxymethotrexate (7-OH-MTX) is the main metabolite in serum following MTX infusion, ${ }^{62}$ and it contributes to activity and toxicity. The concentrations of 7-OH-MTX exceed those of the parent compound in plasma shortly after the infusion. ${ }^{63}$ Both MTX and 7-OH-MTX exhibit first-order pharmacokinetics. ${ }^{62}$ MTX is eliminated by renal excretion involving passive glomerular filtration and active tubular reabsorption and secretion. 7-OH-MTX is also renally cleared but more slowly than MTX. Renal elimination is prolonged in patients with renal impairment or third-space fluid collections, due to slow redistribution of MTX from these extravascular compartments. ${ }^{62} \mathrm{MTX}$ is prone to drugdrug interactions, especially nonsteroidal antirheumatics (NSARs). ${ }^{64}$ The uptake of MTX into the cell is primarily mediated by the RFC and, to a lesser amount, by the FR- $\alpha$. Intracellularly, MTX undergoes extensive $\gamma$-polyglutamation by FPGS, and these negatively charged polyglutamates are retained intracellularly. Polyglutamates can also undergo hydrolation by $\gamma$-glutamyl hydrolase (GGH, also known as folylpolyglutamate hydrolase or FPGH) into short-chain polyglutamates. ${ }^{65,66}$ The MTX pentaglutamate moiety is most active, with $K_{i}$ values 100 times below $K_{i}$ values of the nonglutamated compound.

\section{High-dose MTX}

MTX at doses $\geq 1 \mathrm{~g} / \mathrm{m}^{2}$ is the backbone for treating diseases such as primary central nervous system lymphoma (PCNSL), 
osteosarcoma, or ALL. Careful patient selection, adequate hydration and urinary alkalinization, avoidance of drug interactions, drainage of third-space fluids, and TDM with appropriate adjustment of leucovorin (LV) rescue make HDMTX a well-tolerated treatment option most of the time. $\mathrm{LV}$ rescue starts $24 \mathrm{~h}$ after the start of MTX infusion at a dose of $15 \mathrm{mg} / \mathrm{m}^{2}$ IV push every $6 \mathrm{~h}$ for 3 days and should be continued until serum MTX concentrations drop below $0.05 \mu \mathrm{mol} / \mathrm{L}$. Despite supporting measures, acute renal failure is seen in $\leq 2 \%$ of patients receiving HDMTX, as a consequence of the precipitation of MTX and 7-OH-MTX in the kidney tubules. ${ }^{67}$ Because of considerable interpatient variability, TDM is essential to identify patients at high risk for severe toxicity, and the need for increased hydration or prolonged LV rescue. Before TDM with supplemental LV rescue was incorporated into HDMTX regimens, toxicity was substantial, including a $6 \%$ fatality rate; ${ }^{68} 80 \%$ of these fatalities were attributed to severe myelosuppression, which resulted in either sepsis or hemorrhage, and 20\% were attributed to renal failure. Conventional treatment for HDMTXinduced renal dysfunction includes prompt escalation of LV rescue and adequate hydration and urine alkalinization, provided adequate urine output can be maintained. MTX removal by hemodialysis is of potential value in refractory cases. Finally, carboxypeptidase-G2 (CPDG2), a recombinant bacterial enzyme that hydrolyzes MTX to the inactive metabolite 2,4-diamino-N10-methylpteroic acid (DAMPA), is another option in refractory cases of MTX-associated renal dysfunction. CPDG2 lowers plasma concentrations of MTX within 15 min of administration by roughly $99 \%{ }^{69}$ More recent studies suggest individual exposure to MTX to be an important predictor of a favorable treatment response in patients with PCNSL, ${ }^{14,15}$ but this awaits prospective validation.

\section{Raltitrexed}

Raltitrexed is a selective and direct TYMS inhibitor. As an analog of the THF cofactor, it cannot be incorporated into DNA, and cellular accumulation of dUMP does not result in resistance to raltitrexed. ${ }^{70}$ Its long-lasting inhibition of TYMS allows a convenient 3-weekly schedule of administration. Raltitrexed is approved in many countries (except the United States) for advanced colorectal cancer, but its utilization is mainly limited to patients who are intolerant to 5-fluorouracil (5-FU). Although raltitrexed proved to be equally active to 5-FU/LV in advanced colorectal cancer, there were some raltitrexed-associated deaths due to combined gastrointestinal and hematologic toxicity. ${ }^{71}$ Combining the phase III
MCRC trials, raltitrexed-related mortality $(1.6 \%-4 \%)$ was greater than with 5 -FU $(1.2 \%-2.8 \%){ }^{72}$ This occurred in spite of a significantly lower all-cause serious toxicity rate with raltitrexed and has been attributed to administration of raltitrexed after a toxic event or in the presence of renal impairment. ${ }^{73}$ Patient education, monitoring of renal function, and supportive measures are essential in the management of patients receiving raltitrexed..$^{74}$

\section{Pharmacology}

Raltitrexed predominantly enters the cell by RFC and then undergoes polyglutamation, with the polyglutamated form again being more potent than the parent compound. With repeated administration at 3-weekly intervals, no clinically significant accumulation of raltitrexed was found in patients with normal renal function. ${ }^{75}$ Raltitrexed is contraindicated in patients with severe renal or hepatic impairment and/or clinically significant cardiac arrhythmias requiring drug therapy. The importance of dose reductions in patients with reduced creatinine clearance is critical in preventing subsequent severe toxicity. In patients after accidental overdosing or those suffering from severe toxicity, LV rescue is of potential value.

\section{Pralatrexate}

Pralatrexate (PDX; 10'-propargyl 10'-deazaaminopterin) is a newer antifolate that was rationally designed to have a high affinity for the RFC, resulting in increased cellular internalization. ${ }^{76}$ In a phase II lymphoma study, PDX demonstrated some activity against peripheral T-cell lymphoma (TCL). ${ }^{77}$ Subsequently, the multicenter confirmatory phase II PROPEL (Pralatrexate in Relapsed or Refractory Peripheral T-cell Lymphoma) trial has led to the approval of PDX in the United States for relapsed or refractory TCL. ${ }^{78,79}$ Treatment response in a total of 109 evaluable patients in the PROPEL trial was $29 \%$, with 12 patients (11\%) achieving a complete response. ${ }^{79}$ The median duration of response was 10.1 months. Mucosal inflammation was seen in $>70 \%$ of patients but was usually mild to moderate. Hematological toxicity consists of severe thrombocytopenia in a third of patients and severe anemia in $16 \%$ of patients. Febrile neutropenia was noted in $5 \%$ of cases. Patients should receive supplementation with $\mathrm{B}_{12}$ and folic acid to avoid severe toxicity.

PDX was rationally designed to have high affinity for the RFC, which leads to better cellular internalization of the drug and a greater antitumor effect when compared with MTX. ${ }^{80}$ The structural difference between PDX and MTX is based on the presence of a propargyl group substitution at 
carbon 10 instead of the methyl group in MTX. The basis of increased efficacy of PDX in vitro is based on its increased affinity for the RFC, but whether this is enough to overcome MTX resistance is unknown. PDX effectively binds to and inactivates DHFR, depleting intracellular reduced folate stores and blocking DNA synthesis.

\section{Lometrexol}

Lometrexol (LMTX) is a potent and selective inhibitor of GARFT, with broad antitumor spectrum. GARFT catalyzes the formation of purines from the reaction of $10^{\prime}$ formyltetrahydrofolate $\left(10^{\prime}-\mathrm{FTHF}\right)$ to THF. Its inhibition results in a depletion of intracellular purine levels. LMTX enters the cell via the RFC and undergoes extensive polyglutamation, with a slow elimination of polyglutamates. Without folic acid supplementation, severe cumulative myelosuppression and mucositis are likely. ${ }^{81}$ At present, LMTX is not approved as an anticancer agent.

\section{Edatrexate}

Edatrexate (EDX) is a classic antifolate with a more efficient intracellular polyglutamation compared with MTX ${ }^{82}$ EDX polyglutamates are potent inhibitors of DHFR but less potent inhibitors of TYMS. ${ }^{83}$ EDX exhibits saturable, nonlinear Michaelis-Menten pharmacokinetics, with $\leq 55 \%$ of EDX undergoing renal excretion as unchanged parent compound..$^{84}$ As EDX was associated with severe stomatitis, toxic dermatitis, and even fatalities, ${ }^{85}$ clinical development was halted.

\section{Nonpolyglutamable classical antifolates \\ Talotrexin}

Talotrexin (PT-523) is a newer antifolate and potent antagonist of DHFR. Talotrexin combines characteristics of both the classical and nonclassical antifolates. As talotrexin does not contain a glutamic acid side chain, it is not converted to intracellular polyglutamates, with a potential advantage for drug safety and less bone marrow toxicity. ${ }^{86}$ The drug binds tightly to DHFR, with an inhibitory constant $\left(K_{i}\right)$ of $0.35 \mathrm{pmol} / \mathrm{L}, 15$-fold lower than for MTX. Talotrexin exhibits linear pharmacokinetics with a rapid initial disposition phase. ${ }^{87}$ Patients with relapsed or refractory leukemia or MDS received talotrexin for five subsequent days, together with supplemental folic acid and vitamin $\mathrm{B}_{12}{ }^{87}$ Dose-limiting toxicity was stomatitis, and talotrexin $0.6 \mathrm{mg} / \mathrm{m}^{2} /$ day for 5 days every 3 weeks was recommended for phase II studies, where evaluation in patients with refractory ALL is ongoing. ${ }^{87}$

\section{Nonclassical antifolates}

Nonclassical antifolates do not contain glutamic acid and are not polyglutamable; they are more lipophilic than the classical antifolates and enter cells by passive diffusion.

\section{TMQ}

TMQ is a nonclassical, lipophilic quinazoline derivative with a high inhibitory potency toward DHFR. ${ }^{88}$ Because of its lipophilicity, TMQ can rapidly enter cells by a nonenergy-dependent process. Unlike most antifolate drugs, TMQ is mainly eliminated by hepatic metabolism instead of renal excretion, with a terminal elimination half-life of 15-20 h. ${ }^{88}$ Cell lines resistant to MTX because of deficiencies in folate transport generally retain their sensitivity to TMQ. As TMQ lacks the glutamic acid side chain, it cannot be polyglutamated and is not retained within the cell for prolonged periods of time. ${ }^{89}$ Although TMQ has undergone broad phase II testing in solid tumors, ${ }^{90}$ results were disappointing and there is no current indication in oncology.

\section{Piritrexim}

Piritrexim (PTX) is an oral lipophilic antifolate that is not a substrate of the active folate transport systems but enters cells via an energy-independent process and is effective against cancer cells resistant to MTX because of transport defects. ${ }^{91}$ PTX is not polyglutamated by FPGS, but it is a potent inhibitor of DHFR and TYMS. Oral absorption of PTX is rapid, with an overall bioavailability of $75 \%-95 \% .{ }^{92}$ The terminal halflife following oral administration is $4.5-5.6 \mathrm{~h},{ }^{92}$ with hepatic metabolism being the primary route of drug clearance. Despite the potential as an oral antifolate, PTX did not show any therapeutic advantage over more established antifolates.

\section{Nolatrexed}

Nolatrexed (Thymitaq, TM) is a nonclassical, lipophilic antifolate and a noncompetitive, high-affinity TYMS inhibitor. TM causes extensive dTMP depletion and dUMP accumulation, causing thymineless cell death. TM is not dependent on the cell cycle, as high concentrations of TM failed to induce S-phase arrest but still resulted in apoptosis. ${ }^{93}$ Although TM itself is lipophilic, it can be administered via intravenous infusion as a water-soluble dihydrochloride salt. Due to its lipophilicity, TM enters cells by passive diffusion and does not undergo polyglutamation. ${ }^{94}$ TM was granted orphan drug status for the treatment of unresectable hepatocellular carcinoma by the US Food and Drug Administration (2001) and the European Medicines Agency (2007), based on a randomized phase III Asian study comparing TM with 
doxorubicin, and two North American phase II studies. ${ }^{95}$ TM has never gained widespread use in oncology.

\section{MTA}

\section{Pemetrexed}

Pemetrexed has been approved in combination with cisplatin as a first-line treatment for advanced non-squamous-cell lung cancer, ${ }^{10}$ as a single agent for relapsed NSCLC after platinum-containing chemotherapy, ${ }^{96}$ and in combination with cisplatin for the treatment of pleural mesothelioma. ${ }^{9}$ Important is histotype-selective activity of pemetrexed, with a significant benefit seen only in patients with non-squamouscell lung cancer, ${ }^{10}$ potentially as a consequence of increased TYMS expression in tumors of squamous histology. ${ }^{97}$ Supportive treatment with oral folic acid $0.5 \mathrm{mg} /$ day and intramuscular vitamin $B_{12} 1 \mathrm{mg}$ every 9 weeks is routinely used, as it has been shown to reduce the incidence of potentially fatal myelosuppression. ${ }^{98}$ Pemetrexed is a cell-cycle-dependent antifolate with a 6-5-fused pyrrolopyrimidine-based nucleus, ${ }^{99}$ and it inhibits TYMS, DHFR, GARFT, AICARFT, and C1-THF synthase, which catalyzes the incorporation of a formyl group into $10^{\prime}$-FTHF for purine synthesis, and the incorporation of a methylene group into $5^{\prime}, 10^{\prime}$-MTHF for thymidylate synthesis. Mechanisms of resistance include diminished accumulation of pemetrexed polyglutamates due to decreased activity of FPGS, ${ }^{100}$ increased enzymatic cleavage of pemetrexed poly- $\gamma$-glutamates by high intracellular GH activity, and TYMS amplification. ${ }^{101}$ Inhibition of TYMS leads to intracellular accumulation of dUMP and subsequent efflux of deoxyuridine (dUrd) into the circulation, which can be used as a pharmacodynamic marker of in vivo TYMS inhibition following administration of pemetrexed. ${ }^{102}$

\section{Pharmacology}

Pemetrexed is transported into cells mainly by the RFC and undergoes rapid intracellular transformation by FPGS to the more potent polyglutamate derivatives. ${ }^{103}$ Pemetrexed has a small steady-state volume of distribution of about $15 \mathrm{~L}$ and is rapidly eliminated from plasma with a terminal elimination half-life of between 2 and $5 \mathrm{~h}$ at doses of 525-700 $\mathrm{mg} / \mathrm{m}^{2}$. Pemetrexed undergoes mainly urinary excretion as an unchanged parent compound. Furthermore, pemetrexed exhibits dose-proportional increases in plasma concentration and no signs of accumulation in patients with normal renal function. Third-space accumulation seems not to play a clinically significant role. ${ }^{104}$ As pemetrexed is often combined with potentially nephrotoxic cisplatin, adequate monitoring of renal function is important. Recommendations for the management of pemetrexed toxicity in the presence of renal failure have not been established, but treatment options with LV, folate, thymidine, carboxypeptidase, or hemodialysis are all possible. ${ }^{105}$ Homocysteine is a marker for overall folate status in the body and predicted severe pemetrexed-associated toxicity in a clinical study. ${ }^{106}$

\section{Summary}

The approval of pemetrexed for the first-line treatment of non-squamous-cell lung cancer, second-line treatment of NSCLC, and first-line treatment of malignant pleural mesothelioma has substantially added to the clinical importance of antifolates in oncology. Treatment individualization ever since has played an important role in the development of antifolate drugs. Although LV rescue and TDM are standard for HDMTX regimens, and folate and $\mathrm{B}_{12}$ supplementation is standard for pemetrexed to increase MTD, new strategies will include pharmacogenetic markers such as tumoral TYMS expression for further improvement of antifolate treatment.

\section{Disclosure}

The authors report no conflicts of interest in this work.

\section{References}

1. Farber S, Cutler EC, Hawkins JW, Harrison JH, Peirce EC 2nd, Lenz GG. The action of pteroylglutamic conjugates on man. Science. 1947; 106(2764):619-621.

2. Farber S, Diamond LK. Temporary remissions in acute leukemia in children produced by folic acid antagonist, 4-aminopteroyl-glutamic acid. N Engl J Med. 1948;238(23):787-793.

3. Li MC, Hertz R, Bergenstal DM. Therapy of choriocarcinoma and related trophoblastic tumors with folic acid and purine antagonists. $N$ Engl $J$ Med. 1958;259(2):66-74.

4. Kantarjian H, Thomas D, O'Brien S, et al. Long-term follow-up results of hyperfractionated cyclophosphamide, vincristine, doxorubicin, and dexamethasone (Hyper-CVAD), a dose-intensive regimen, in adult acute lymphocytic leukemia. Cancer. 2004;101(12):2788-2801.

5. Bonadonna G, Valagussa P, Moliterni A, Zambetti M, Brambilla C. Adjuvant cyclophosphamide, methotrexate, and fluorouracil in nodepositive breast cancer: the results of 20 years of follow-up. NEngl J Med. 1995;332(14):901-906.

6. Fuchs N, Bielack SS, Epler D, et al. Long-term results of the co-operative German-Austrian-Swiss osteosarcoma study group's protocol COSS-86 of intensive multidrug chemotherapy and surgery for osteosarcoma of the limbs. Ann Oncol. 1998;9(8):893-899.

7. Ferreri AJ, Reni M, Dell'Oro S, et al. Combined treatment with high-dose methotrexate, vincristine and procarbazine, without intrathecal chemotherapy, followed by consolidation radiotherapy for primary central nervous system lymphoma in immunocompetent patients. Oncology. 2001;60(2):134-140.

8. Guardiola E, Peyrade F, Chaigneau L, et al. Results of a randomised phase II study comparing docetaxel with methotrexate in patients with recurrent head and neck cancer. Eur J Cancer. 2004;40(14):2071-2076.

9. Vogelzang NJ, Rusthoven JJ, Symanowski J, et al. Phase III study of pemetrexed in combination with cisplatin versus cisplatin alone in patients with malignant pleural mesothelioma. J Clin Oncol. 2003;21(14): 2636-2644. 
10. Scagliotti GV, Parikh P, von Pawel J, et al. Phase III study comparing cisplatin plus gemcitabine with cisplatin plus pemetrexed in chemotherapy-naive patients with advanced-stage non-small-cell lung cancer. J Clin Oncol. 2008;26(21):3543-3551.

11. Buikhuisen WA, Burgers JA, Vincent AD, et al. Pemetrexed pathwayassociated germline polymorphisms: a useful tool for treatment individualization? J Clin Oncol. 2010;28(27):e482-e483.

12. Chen JS, Chao Y, Bang YJ, et al. A phase I/II and pharmacogenomic study of pemetrexed and cisplatin in patients with unresectable advanced gastric carcinoma. Anticancer Drugs. 2010;21(8):777-784.

13. Smit EF, Burgers SA, Biesma B, et al. Randomized phase II and pharmacogenetic study of pemetrexed compared with pemetrexed plus carboplatin in pretreated patients with advanced non-small-cell lung cancer. J Clin Oncol. 2009;27(12):2038-2045.

14. Ferreri AJ, Guerra E, Regazzi M, et al. Area under the curve of methotrexate and creatinine clearance are outcome-determining factors in primary CNS lymphomas. Br J Cancer. 2004;90(2):353-358.

15. Joerger M, Huitema AD, Krahenbuhl S, et al. Methotrexate area under the curve is an important outcome predictor in patients with primary CNS lymphoma: a pharmacokinetic-pharmacodynamic analysis from the IELSG no. 20 trial. Br J Cancer. 2010;102(4):673-677.

16. Zhao R, Matherly LH, Goldman ID. Membrane transporters and folate homeostasis: intestinal absorption and transport into systemic compartments and tissues. Expert Rev Mol Med. 2009;11:e4.

17. Chen G, Wright JE, Rosowsky A. Dihydrofolate reductase binding and cellular uptake of nonpolyglutamatable antifolates: correlates of cytotoxicity toward methotrexate-sensitive and -resistant human head and neck squamous carcinoma cells. Mol Pharmacol. 1995;48(4) 758-765.

18. Goldman ID. The characteristics of the membrane transport of amethopterin and the naturally occurring folates. Ann N Y Acad Sci. 1971; 186:400-422.

19. Goldman ID, Lichtenstein NS, Oliverio VT. Carrier-mediated transport of the folic acid analogue, methotrexate, in the L1210 leukemia cell. J Biol Chem. 1968;243(19):5007-5017.

20. Whetstine JR, Flatley RM, Matherly LH. The human reduced folate carrier gene is ubiquitously and differentially expressed in normal human tissues: identification of seven non-coding exons and characterization of a novel promoter. Biochem J. 2002;367(Pt 3):629-640.

21. Ross JF, Chaudhuri PK, Ratnam M. Differential regulation of folate receptor isoforms in normal and malignant tissues in vivo and in established cell lines. Physiologic and clinical implications. Cancer. 1994; 73(9):2432-2443.

22. Wu M, Gunning W, Ratnam M. Expression of folate receptor type alpha in relation to cell type, malignancy, and differentiation in ovary, uterus, and cervix. Cancer Epidemiol Biomarkers Prev. 1999;8(9):775-782.

23. Shen F, Wang H, Zheng X, Ratnam M. Expression levels of functional folate receptors alpha and beta are related to the number of N-glycosylated sites. Biochem J. 1997;327(Pt 3):759-764.

24. Shen F, Wu M, Ross JF, Miller D, Ratnam M. Folate receptor type gamma is primarily a secretory protein due to lack of an efficient signal for glycosylphosphatidylinositol modification: protein characterization and cell type specificity. Biochemistry. 1995;34(16): $5660-5665$.

25. Ross JF, Wang H, Behm FG, et al. Folate receptor type beta is a neutrophilic lineage marker and is differentially expressed in myeloid leukemia. Cancer. 1999;85(2):348-357.

26. Shen F, Ross JF, Wang X, Ratnam M. Identification of a novel folate receptor, a truncated receptor, and receptor type beta in hematopoietic cells: cDNA cloning, expression, immunoreactivity, and tissue specificity. Biochemistry. 1994;33(5):1209-1215.

27. Westerhof GR, Schornagel JH, Kathmann I, et al. Carrier- and receptormediated transport of folate antagonists targeting folate-dependent enzymes: correlates of molecular-structure and biological activity. Mol Pharmacol. 1995;48(3):459-471.

28. Andrews NC. When is a heme transporter not a heme transporter? When it's a folate transporter. Cell Metab. 2007;5(1):5-6.
29. Qiu A, Jansen M, Sakaris A, et al. Identification of an intestinal folate transporter and the molecular basis for hereditary folate malabsorption. Cell. 2006;127(5):917-928.

30. Shayeghi M, Latunde-Dada GO, Oakhill JS, et al. Identification of an intestinal heme transporter. Cell. 2005;122(5):789-801.

31. Kruh GD, Belinsky MG. The MRP family of drug efflux pumps. Oncogene. 2003;22(47):7537-7552.

32. Wielinga P, Hooijberg JH, Gunnarsdottir S, et al. The human multidrug resistance protein MRP5 transports folates and can mediate cellular resistance against antifolates. Cancer Res. 2005;65(10):4425-4430.

33. Allegra CJ, Hoang K, Yeh GC, Drake JC, Baram J. Evidence for direct inhibition of de novo purine synthesis in human MCF-7 breast cells as a principal mode of metabolic inhibition by methotrexate. $J$ Biol Chem. 1987;262(28):13520-13526.

34. Baugh CM, Krumdieck CL, Nair MG. Polygammaglutamyl metabolites of methotrexate. Biochem Biophys Res Commun. 1973;52(1):27-34.

35. Curt GA, Jolivet J, Carney DN, et al. Determinants of the sensitivity of human small-cell lung cancer cell lines to methotrexate. $J$ Clin Invest. 1985;76(4):1323-1329.

36. Fabre I, Fabre G, Goldman ID. Polyglutamylation, an important element in methotrexate cytotoxicity and selectivity in tumor versus murine granulocytic progenitor cells in vitro. Cancer Res. 1984;44(8):3190-3195.

37. Rosowsky A, Wright JE, Vaidya CM, Forsch RA. The effect of side-chain, para-aminobenzoyl region, and B-ring modifications on dihydrofolate reductase binding, influx via the reduced folate carrier, and cytotoxicity of the potent nonpolyglutamatable antifolate N(alpha)(4-amino-4-deoxypteroyl)-N(delta)-hemiphthaloyl-L-ornithine. Pharmacol Ther. 2000;85(3):191-205.

38. Banerjee D, Mayer-Kuckuk P, Capiaux G, Budak-Alpdogan T, Gorlick R, Bertino JR. Novel aspects of resistance to drugs targeted to dihydrofolate reductase and thymidylate synthase. Biochim Biophys Acta. 2002;1587(2-3):164-173.

39. Osborn MJ, Freeman M, Huennekens FM. Inhibition of dihydrofolic reductase by aminopterin and amethopterin. Proc Soc Exp Biol Med. 1958;97(2):429-431.

40. Johnson JM, Meiering EM, Wright JE, Pardo J, Rosowsky A, Wagner G. NMR solution structure of the antitumor compound PT523 and NADPH in the ternary complex with human dihydrofolate reductase. Biochemistry. 1997;36(15):4399-4411.

41. Brigle KE, Spinella MJ, Sierra EE, Goldman ID. Characterization of a mutation in the reduced folate carrier in a transport defective L1210 murine leukemia cell line. J Biol Chem. 1995;270(39):22974-22979.

42. Drori S, Jansen G, Mauritz R, Peters GJ, Assaraf YG. Clustering of mutations in the first transmembrane domain of the human reduced folate carrier in GW1843U89-resistant leukemia cells with impaired antifolate transport and augmented folate uptake. J Biol Chem. 2000; 275(40):30855-30863.

43. Jansen G, Mauritz R, Drori S, et al. A structurally altered human reduced folate carrier with increased folic acid transport mediates a novel mechanism of antifolate resistance. J Biol Chem. 1998;273(46): 30189-30198.

44. Gorlick R, Goker E, Trippett T, et al. Defective transport is a common mechanism of acquired methotrexate resistance in acute lymphocytic leukemia and is associated with decreased reduced folate carrier expression. Blood. 1997;89(3):1013-1018.

45. Matherly LH, Taub JW, Ravindranath Y, et al. Elevated dihydrofolate reductase and impaired methotrexate transport as elements in methotrexate resistance in childhood acute lymphoblastic leukemia. Blood. 1995;85(2):500-509.

46. Rothem L, Aronheim A, Assaraf YG. Alterations in the expression of transcription factors and the reduced folate carrier as a novel mechanism of antifolate resistance in human leukemia cells. J Biol Chem. 2003; 278(11):8935-8941

47. Chango A, Emery-Fillon N, de Courcy GP, et al. A polymorphism $(80 \mathrm{G}->\mathrm{A})$ in the reduced folate carrier gene and its associations with folate status and homocysteinemia. Mol Genet Metab. 2000; 70(4):310-315. 
48. Laverdiere C, Chiasson S, Costea I, Moghrabi A, Krajinovic M. Polymorphism G80A in the reduced folate carrier gene and its relationship to methotrexate plasma levels and outcome of childhood acute lymphoblastic leukemia. Blood. 2002;100(10):3832-3834.

49. Yang R, Qin J, Hoang BH, Healey JH, Gorlick R. Polymorphisms and methylation of the reduced folate carrier in osteosarcoma. Clin Orthop Relat Res. 2008;466(9):2046-2051.

50. Toffoli G, Russo A, Gallo A, et al. Expression of folate binding protein as a prognostic factor for response to platinum-containing chemotherapy and survival in human ovarian cancer. Int J Cancer. 1998;79(2):121-126.

51. Hsueh CT, Dolnick BJ. Regulation of folate-binding protein gene expression by DNA methylation in methotrexate-resistant KB cells. Biochem Pharmacol. 1994;47(6):1019-1027.

52. Diop-Bove NK, Wu J, Zhao R, Locker J, Goldman ID. Hypermethylation of the human proton-coupled folate transporter (SLC46A1) minimal transcriptional regulatory region in an antifolate-resistant HeLa cell line. Mol Cancer Ther. 2009;8(8):2424-2431.

53. Chen ZS, Lee K, Walther S, et al. Analysis of methotrexate and folate transport by multidrug resistance protein 4 (ABCC4): MRP4 is a component of the methotrexate efflux system. Cancer Res. 2002;62(11): 3144-3150.

54. Sirotnak FM, Wendel HG, Bornmann WG, et al. Co-administration of probenecid, an inhibitor of a cMOAT/MRP-like plasma membrane ATPase, greatly enhanced the efficacy of a new 10-deazaaminopterin against human solid tumors in vivo. Clin Cancer Res. 2000;6(9): 3705-3712.

55. Bram E, Ifergan I, Shafran A, Berman B, Jansen G, Assaraf YG. Mutant Gly482 and Thr482 ABCG2 mediate high-level resistance to lipophilic antifolates. Cancer Chemother Pharmacol. 2006;58(6):826-834.

56. Shafran A, Ifergan I, Bram E, et al. ABCG2 harboring the Gly482 mutation confers high-level resistance to various hydrophilic antifolates. Cancer Res. 2005;65(18):8414-8422.

57. Gifford AJ, Kavallaris M, Madafiglio J, et al. P-glycoprotein-mediated methotrexate resistance in CCRF-CEM sublines deficient in methotrexate accumulation due to a point mutation in the reduced folate carrier gene. Int J Cancer. 1998;78(2):176-181.

58. Horns RC Jr, Dower WJ, Schimke RT. Gene amplification in a leukemic patient treated with methotrexate. J Clin Oncol. 1984;2(1):2-7.

59. Trent JM, Buick RN, Olson S, Horns RC Jr, Schimke RT. Cytologic evidence for gene amplification in methotrexate-resistant cells obtained from a patient with ovarian adenocarcinoma. J Clin Oncol. 1984; 2(1):8-15.

60. Li WW, Lin JT, Tong WP, Trippett TM, Brennan MF, Bertino JR. Mechanisms of natural resistance to antifolates in human soft tissue sarcomas. Cancer Res. 1992;52(6):1434-1438.

61. Spencer HT, Sorrentino BP, Pui CH, Chunduru SK, Sleep SE, Blakley RL. Mutations in the gene for human dihydrofolate reductase: an unlikely cause of clinical relapse in pediatric leukemia after therapy with methotrexate. Leukemia. 1996;10(3):439-446.

62. Jolivet J, Cowan KH, Curt GA, Clendeninn NJ, Chabner BA. The pharmacology and clinical use of methotrexate. $N$ Engl J Med. 1983; 309(18):1094-1104

63. Erttmann R, Bielack S, Landbeck G. Kinetics of 7-hydroxy-methotrexate after high-dose methotrexate therapy. Cancer Chemother Pharmacol. 1985;15(2):101-104.

64. Joerger M, Huitema AD, van den Bongard HJ, et al. Determinants of the elimination of methotrexate and 7-hydroxy-methotrexate following high-dose infusional therapy to cancer patients. Br J Clin Pharmacol. 2006;62(1):71-80.

65. Moran RG. Roles of folylpoly-gamma-glutamate synthetase in therapeutics with tetrahydrofolate antimetabolites: an overview. Semin Oncol. 1999;26(2 Suppl 6):24-32.

66. Galivan J, Ryan T, Rhee M, Yao R, Chave K. Glutamyl hydrolase: properties and pharmacologic impact. Semin Oncol. 1999;26(2 Suppl 6): 33-37.

67. Widemann BC, Adamson PC. Understanding and managing methotrexate nephrotoxicity. Oncologist. 2006;11(6):694-703.
68. von Hoff DD, Penta JS, Helman LJ, Slavik M. Incidence of drug-related deaths secondary to high-dose methotrexate and citrovorum factor administration. Cancer Treat Rep. 1977;61(4):745-748.

69. Green MR, Chamberlain MC. Renal dysfunction during and after high-dose methotrexate. Cancer Chemother Pharmacol. 2009;63(4): 599-604.

70. Salonga D, Danenberg KD, Johnson M, et al. Colorectal tumors responding to 5-fluorouracil have low gene expression levels of dihydropyrimidine dehydrogenase, thymidylate synthase, and thymidine phosphorylase. Clin Cancer Res. 2000;6(4):1322-1327.

71. Maughan T, James R, Kerr D, et al. Excess treatment related deaths and impaired quality of life show raltitrexed is inferior to infusional $5 \mathrm{FU}$ regimen in the palliative chemotherapy of advanced colorectal cancer (CRC): final results of MRC CRO6 [abstract]. Ann Oncol. 2000; 11 Suppl 4:43.

72. Cunningham D, Zalcberg J, Maroun J, et al. Efficacy, tolerability and management of raltitrexed (Tomudex) monotherapy in patients with advanced colorectal cancer: a review of phase II/III trials. Eur J Cancer. 2002;38(4):478-486.

73. Thomas RJ, Williams M, Garcia-Vargas J. Lessons learned from raltitrexed-quality assurance, patient education and intensive supportive drugs to optimise tolerability. Clin Oncol (R Coll Radiol). 2003;15(5): 227-232.

74. Ford HE, Cunningham D. Safety of raltitrexed. Lancet. 1999;354(9192): 1824-1825.

75. Clarke SJ, Beale PJ, Rivory LP. Clinical and preclinical pharmacokinetics of raltitrexed. Clin Pharmacokinet. 2000;39(6):429-443.

76. Sirotnak FM, DeGraw JI, Moccio DM, Samuels LL, Goutas LJ. New folate analogs of the 10-deaza-aminopterin series. Basis for structural design and biochemical and pharmacologic properties. Cancer Chemother Pharmacol. 1984;12(1):18-25.

77. O'Connor OA, Horwitz S, Hamlin P, et al. Phase II-I-II study of two different doses and schedules of pralatrexate, a high-affinity substrate for the reduced folate carrier, in patients with relapsed or refractory lymphoma reveals marked activity in T-cell malignancies. J Clin Oncol. 2009;27(26):4357-4364.

78. Thompson CA. FDA approves pralatrexate for treatment of rare lymphoma. Am J Health Syst Pharm. 2009;66(21):1890.

79. O'Connor O, Pro B, Pinter-Brown L, et al. Results of the pivotal, multicenter, phase II study of pralatrexate in patients with relapsed or refractory peripheral T-cell lymphoma (PTCL). J Clin Oncol. 2009; 27 Suppl 15:449s. Abstract 8561.

80. Matherly LH, Hou Z, Deng Y. Human reduced folate carrier: translation of basic biology to cancer etiology and therapy. Cancer Metastasis Rev. 2007;26(1):111-128.

81. Ray MS, Muggia FM, Leichman CG, et al. Phase I study of (6R)-5, 10-dideazatetrahydrofolate: a folate antimetabolite inhibitory to de novo purine synthesis. J Natl Cancer Inst. 1993;85(14):1154-1159.

82. Jolivet J, Jansen G, Peters GJ, Pinard MF, Schornagel JH. Leucovorin rescue of human cancer and bone marrow cells following edatrexate or methotrexate. Biochem Pharmacol. 1994;47(4):659-665.

83. Grant SC, Kris MG, Young CW, Sirotnak FM. Edatrexate, an antifolate with antitumor activity: a review. Cancer Invest. 1993;11(1):36-45.

84. Kris MG, Kinahan JJ, Gralla RJ, et al. Phase I trial and clinical pharmacological evaluation of 10-ethyl-10-deazaaminopterin in adult patients with advanced cancer. Cancer Res. 1988;48(19):5573-5579.

85. Schornagel JH, Verweij J, de Mulder PH, et al. Randomized phase III trial of edatrexate versus methotrexate in patients with metastatic and/or recurrent squamous cell carcinoma of the head and neck: a European Organization for Research and Treatment of Cancer Head and Neck Cancer Cooperative Group study. J Clin Oncol. 1995;13(7): 1649-1655.

86. Rosowsky A. PT523 and other aminopterin analogs with a hemiphthaloyl-L-ornithine side chain: exceptionally tight-binding inhibitors of dihydrofolate reductase which are transported by the reduced folate carrier but cannot form polyglutamates. Curr Med Chem. 1999;6(4):329-352. 
87. Giles F, Rizzieri DA, George S, et al. A phase I study of talvesta (talotrexin) in relapsed or refractory leukemia or myelodysplastic syndrome. Blood (ASH Annual Meeting Abstracts). 2006;108(11):1968.

88. Marshall JL, DeLap RJ. Clinical pharmacokinetics and pharmacology of trimetrexate. Clin Pharmacokinet. 1994;26(3):190-200.

89. Fleming GF, Schilsky RL. Antifolates: the next generation. Semin Oncol. 1992;19(6):707-719.

90. Takimoto $\mathrm{CH}$. New antifolates: pharmacology and clinical applications. Oncologist. 1996;1(1 and 2):68-81.

91. Taylor IW, Slowiaczek P, Friedlander ML, Tattersall MH. Selective toxicity of a new lipophilic antifolate, BW301U, for methotrexate-resistant cells with reduced drug uptake. Cancer Res. 1985;45(3): 978-982.

92. Adamson PC, Balis FM, Miser J, et al. Pediatric phase I trial, pharmacokinetic study, and limited sampling strategy for piritrexim administered on a low-dose, intermittent schedule. Cancer Res. 1992; 52(3):521-524.

93. Sakoff JA, Ackland SP. Thymidylate synthase inhibition induces S-phase arrest, biphasic mitochondrial alterations and caspasedependent apoptosis in leukaemia cells. Cancer Chemother Pharmacol. 2000;46(6):477-487.

94. van der Wilt CL, Smid K, Peters GJ. Effects of antifolates on the binding of 5-fluoro-2'-deoxyuridine monophosphate to thymidylate synthase. Biochem Pharmacol. 2002;64(4):669-675.

95. Jhawer M, Rosen L, Dancey J, et al. Phase II trial of nolatrexed dihydrochloride [Thymitaq, AG 337] in patients with advanced hepatocellular carcinoma. Invest New Drugs. 2007;25(1):85-94.

96. Hanna N, Shepherd FA, Fossella FV, et al. Randomized phase III trial of pemetrexed versus docetaxel in patients with non-small-cell lung cancer previously treated with chemotherapy. J Clin Oncol. 2004; 22(9):1589-1597.
97. Selvaggi G, Scagliotti GV. Histologic subtype in NSCLC: does it matter? Oncology (Williston Park). 2009;23(13):1133-1140.

98. Niyikiza C, Hanauske AR, Rusthoven JJ, et al. Pemetrexed safety and dosing strategy. Semin Oncol. 2002;29(6 Suppl 18):24-29.

99. Goldman ID, Zhao R. Molecular, biochemical, and cellular pharmacology of pemetrexed. Semin Oncol. 2002;29(6 Suppl 18):3-17.

100. Pizzorno G, Moroson BA, Cashmore AR, et al. Multifactorial resistance to 5,10-dideazatetrahydrofolic acid in cell lines derived from human lymphoblastic leukemia CCRF-CEM. Cancer Res. 1995;55(3): 566-573.

101. Rhee MS, Ryan TJ, Galivan J. Glutamyl hydrolase and the multitargeted antifolate LY231514. Cancer Chemother Pharmacol. 1999; 44(5):427-432.

102. de Jonge MJ, Punt CJ, Sparreboom A, et al. Phase I and pharmacologic study of oral ZD9331, a novel nonpolyglutamated thymidylate synthase inhibitor, in adult patients with solid tumors. J Clin Oncol. 2002;20(7):1923-1931.

103. Calvert AH. Biochemical pharmacology of pemetrexed. Oncology (Williston Park). 2004;18(13 Suppl 8):13-17.

104. Dickgreber NJ, Sorensen JB, Paz-Ares LG, et al. Pemetrexed safety and pharmacokinetics in patients with third-space fluid. Clin Cancer Res. 2010;16(10):2872-2880.

105. Brandes JC, Grossman SA, Ahmad H. Alteration of pemetrexed excretion in the presence of acute renal failure and effusions: presentation of a case and review of the literature. Cancer Invest 2006;24(3):283-287.

106. Niyikiza C, Baker SD, Seitz DE, et al. Homocysteine and methylmalonic acid: markers to predict and avoid toxicity from pemetrexed therapy. Mol Cancer Ther. 2002;1(7):545-552.
Cancer Management and Research

\section{Publish your work in this journal}

Cancer Management and Research is an international, peer-reviewed open access journal focusing on cancer research and the optimal use of preventative and integrated treatment interventions to achieve improved outcomes, enhanced survival and quality of life for the cancer patient The journal welcomes original research, clinical \& epidemiological

\section{Dovepress}

studies, reviews \& evaluations, guidelines, expert opinion \& commentary, case reports \& extended reports. The manuscript management system is completely online and includes a very quick and fair peerreview system, which is all easy to use. Visit http://www.dovepress.com/ testimonials.php to read real quotes from published authors. 